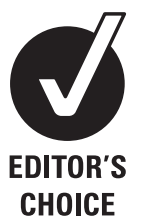

Supplementary material is published online only at http://jech.bmj.com/content/ vol64/issue2

${ }^{1}$ Department of Epidemiology, Center for Social Epidemiology and Population Health,

University of Michigan School of

Public Health, Ann Arbor,

Michigan, USA ${ }^{2}$ University of

Michigan Medical School, Ann

Arbor, Michigan, USA ${ }^{3}$ Survey

Research Center, Institute for

Social Research, University of

Michigan, Ann Arbor, Michigan

USA ${ }^{4}$ Center for Global Health,

University of Michigan, Ann

Arbor, Michigan, USA

Correspondence to

Mr Abdulrahman M El-Sayed, Department of Epidemiology, 109 Observatory Street, Ann Arbor, MI 48109, USA; elabdul@umich.edu

Accepted 16 May 2009

Published Online First

19 August 2009

\title{
Community context, acculturation and low-birth-weight risk among Arab Americans: evidence from the Arab-American birth-outcomes study
}

\author{
Abdulrahman M El-Sayed, ${ }^{1,2}$ Sandro Galea 1,2,3,4
}

\begin{abstract}
Background An assessment was made as to whether maternal residence in areas with high Arab-American concentrations, hence with expected low acculturation for this ethnic group, was associated with low-birthweight $(<2500 \mathrm{~g})(\mathrm{LBW})$ risk among Arab-ethnicity mothers (AEM).
\end{abstract}

Methods Data on all births in Michigan from 2000 to 2005 were collected. Bivariate $\chi^{2}$ tests and multivariable logistic regression models were used to assess the relation between residence in areas with a high Arab-American concentration and risk for LBW among AEM. As a control, analyses were replicated among nonArab white mothers.

Results Both residence in Dearborn $(\mathrm{OR}=0.85,95 \% \mathrm{Cl}$ 0.75 to 0.97$)$, the city with the highest Arab-American concentration in the USA, and residence in 48126 $(\mathrm{OR}=0.81,95 \% \mathrm{Cl} 0.71$ to 0.93$)$, the zip code with the highest concentration of AEM in Dearborn, were associated with a lower risk for LBW compared with residence in the rest of Michigan in multivariable models adjusted for potential confounders. Neither residence in Dearborn nor residence in 48126 was associated with LBW risk among non-Arab white mothers.

Conclusions Residence in areas with high Arab-American concentrations was associated with a lower LBW risk among AEM. Future work should directly measure acculturation, a plausible mediator of this observed relation.

\section{INTRODUCTION}

Arab ethnicity (AE) is associated with a lower risk for adverse birth outcomes compared with nonHispanic Caucasians in both the USA ${ }^{1}$ and Europe. ${ }^{2}$ In the USA, it has been shown that persons with self-reported $\mathrm{AE}$ are $16 \%$ less likely than Caucasians to give birth prematurely. ${ }^{3}$ Understanding the determinants of adverse birth outcomes among groups with systematically better birth outcomes, such as Arab-Americans, might improve our understanding of the social risk factors for adverse birth outcomes in general. However, there is a relative paucity of research that has considered the determinants of adverse birth outcomes among Arab-ethnicity mothers (AEM).

El Reda and colleagues ${ }^{1}$ assessed the birth outcomes of AEM in Michigan. They found that among foreign-born AEM, pregnancy-related hypertension, diabetes and use of Medicaid to pay for hospital expenses were associated with preterm birth (PTB). Among native-born AEM, lack of prenatal care and pregnancy-related hypertension were correlates of PTB. El-Sayed and Galea ${ }^{4}$ showed that differences in rates of maternal marital status, tobacco use and foreign-birth between AEM and white mothers contributed to the association between AEM and lower risk for PTB compared with white mothers.

Cultural factors may be protective against adverse birth outcomes among AEM and may potentially explain some of the observed low risk of PTB among this ethnic group. Although there is no direct evidence to this effect among AEM, studies have linked cultural features to the birth outcomes of another ethnic group, particularly HispanicAmericans. For example, in a prospective study of 1071 low-income, primiparous Mexican-American and African-American mothers, Zambrana and colleagues ${ }^{5}$ found that Mexican-American mothers were less stressed, less likely to abuse substances and more likely to have a positive attitude during pregnancy than their African-American counterparts. Upon controlling for these factors, the difference in risk for adverse birth outcomes between Mexican-American and African-American mothers was attenuated. The authors posited that Mexican culture protects against PTB and low birth weight (LBW) by promoting positive perinatal behaviours and a healthy maternal psychosocial status. Cultural factors have also been proposed as determinants of birth outcomes among other ethnic minority groups, including Samoans. ${ }^{11}$

As ethnic minority persons live and work in the USA and interact with the white majority, they acculturate. ${ }^{12}$ In doing so, they may acquire cultural features from the majority that may mitigate the protection against adverse birth outcomes afforded them by their original cultures. Suggestive evidence about the role of acculturation in the aetiology of adverse birth outcomes among ethnic minorities comes from studies about the birth outcomes of Mexican-Americans in the USA. Scribner and Dwyer $^{13}$ used an acculturation scale to assess the relation between acculturation and risk for LBW. They found that highly acculturated Mexican-American women were at 1.86 times increased risk for LBW than their less acculturated counterparts. Several other studies have corroborated the association between acculturation and risk for adverse birth outcomes among this ethnic group. $^{6-10}$ Moreover, Hyman and Dussault, ${ }^{14}$ assessing the relation between acculturation and 
Table 1 Descriptive statistics and bivariate associations between each covariate and low birth weight among Arab ethnicity and non-Arab white mothers in Michigan between 2000 and 2005

\begin{tabular}{|c|c|c|c|c|c|c|c|c|c|c|}
\hline \multirow[b]{3}{*}{ Mother/infant descriptives } & \multicolumn{5}{|c|}{ Arab ethnicity } & \multicolumn{5}{|c|}{ Non-Arab white } \\
\hline & \multirow[b]{2}{*}{$\mathrm{N}$} & \multirow[b]{2}{*}{$\%$} & \multicolumn{3}{|c|}{ LBW } & \multirow[b]{2}{*}{$\mathrm{N}$} & \multirow[b]{2}{*}{$\%$} & \multicolumn{3}{|c|}{ LBW } \\
\hline & & & $\mathrm{N}$ & $\%$ & $\mathrm{p}$ Value & & & $\mathrm{N}$ & $\%$ & $\mathrm{p}$ Value \\
\hline Total & 21617 & & 1410 & 6.5 & & 594419 & & 40519 & 6.8 & \\
\hline Dearborn & & & & & 0.004 & & & & & 0.108 \\
\hline No & 15009 & 69.4 & 1027 & 6.8 & & 590436 & 99.3 & 40273 & 6.8 & \\
\hline Yes & 6608 & 30.6 & 383 & 5.8 & & 3983 & 0.7 & 246 & 6.2 & \\
\hline 48126 zip code & & & & & $<0.001$ & & & & & 0.366 \\
\hline No & 16286 & 75.3 & 1118 & 6.9 & & 593403 & 99.8 & 40457 & 6.8 & \\
\hline Yes & 5331 & 25.7 & 292 & 5.5 & & 1016 & 0.2 & 62 & 6.1 & \\
\hline Parity & & & & & $<0.001$ & & & & & $<0.001$ \\
\hline 0 & 7398 & 34.2 & 556 & 7.5 & & 234142 & 39.4 & 17205 & 7.4 & \\
\hline 1 & 6166 & 28.5 & 381 & 6.2 & & 198913 & 33.5 & 11760 & 5.9 & \\
\hline 2 & 4147 & 19.2 & 240 & 5.8 & & 101618 & 17.1 & 6606 & 6.5 & \\
\hline $3+$ & 3769 & 17.4 & 223 & 5.9 & & 58350 & 9.8 & 4794 & 8.2 & \\
\hline Unknown & 137 & 0.6 & 10 & 7.3 & & 1396 & 0.2 & 154 & 11 & \\
\hline Marital status & & & & & 0.552 & & & & & $<0.001$ \\
\hline Unmarried & 885 & 4.1 & 62 & 7.0 & & 164803 & 27.7 & 13670 & 8.3 & \\
\hline Married & 20732 & 95.9 & 1348 & 6.5 & & 429616 & 72.3 & 26849 & 6.3 & \\
\hline Maternal age & & & & & $<0.001$ & & & & & $<0.001$ \\
\hline$<20$ & 1211 & 5.6 & 102 & 8.4 & & 48660 & 8.2 & 4049 & 8.3 & \\
\hline $20-25$ & 5333 & 24.7 & 321 & 6.0 & & 136788 & 23.0 & 9109 & 6.7 & \\
\hline $26-30$ & 6646 & 30.8 & 396 & 6.0 & & 171770 & 28.9 & 10639 & 6.2 & \\
\hline $31-35$ & 5236 & 24.2 & 346 & 6.6 & & 155051 & 26.1 & 10050 & 6.5 & \\
\hline $36-40$ & 2541 & 11.7 & 183 & 7.2 & & 68211 & 11.5 & 5308 & 7.8 & \\
\hline $41+$ & 649 & 3.0 & 62 & 9.6 & & 13898 & 2.3 & 1353 & 9.7 & \\
\hline Unknown & 1 & 0.0 & 0 & 0.0 & & 41 & 0.0 & 11 & 0.0 & \\
\hline Education & & & & & 0.136 & & & & & $<0.001$ \\
\hline$<11$ years & 4722 & 21.8 & 331 & 7.0 & & 86481 & 14.6 & 7250 & 8.4 & \\
\hline GED* or equivalent & 7359 & 34.0 & 449 & 6.1 & & 184321 & 31.0 & 12984 & 7.0 & \\
\hline College & 6721 & 31.1 & 452 & 6.7 & & 248870 & 41.9 & 15341 & 6.2 & \\
\hline Masters or above & 2107 & 9.8 & 142 & 6.7 & & 66431 & 11.2 & 4176 & 6.3 & \\
\hline Unknown & 708 & 3.3 & 36 & 5.1 & & 8316 & 1.4 & 768 & 9.2 & \\
\hline Place of birth & & & & & 0.034 & & & & & $<0.001$ \\
\hline Foreign & 17439 & 80.7 & 1107 & 6.4 & & 44372 & 7.5 & 2643 & 6.0 & \\
\hline USA & 4178 & 19.3 & 303 & 7.3 & & 550047 & 92.5 & 37876 & 6.9 & \\
\hline Tobacco use & & & & & 0.411 & & & & & $<0.001$ \\
\hline None & 20520 & 94.9 & 1345 & 6.6 & & 492343 & 82.8 & 30179 & 6.1 & \\
\hline Yes & 1097 & 5.1 & 65 & 5.9 & & 102076 & 17.2 & 10340 & 10.1 & \\
\hline
\end{tabular}

*The General Educational Development examination is a five-part examination that certifies that the taker has academic skills commensurate with a high school graduate in the USA or Canada. LBW, low birth weight.

risk for LBW, found that among five ethnic groups in Quebec, Canada, acculturation was associated with increased LBW risk.

Particularly relevant to our work, Peak and Weeks ${ }^{15}$ articulated a relation between community context, acculturation and birth outcomes among Mexican-Americans. They reasoned that if Mexican culture is protective against adverse birth outcomes among Mexican-Americans, then those living in Mexican enclaves in the USA should have a lower risk for adverse birth outcomes than their counterparts not living in these contexts because ethnic enclaves facilitate ethnic cultural practices and lifestyle. In a study of approximately 150000 births in San Diego County, California, they found that Mexican-American mothers living in Hispanic ethnic enclaves were at a lower risk for LBW compared with those living outside such enclaves. Studies have also shown that Hispanic-Americans living in Hispanic ethnic enclaves are protected against other adverse health outcomes, including all-cause mortality, ${ }^{16}$ asthma ${ }^{17}$ and psychopathology. ${ }^{18}$ Pickett and colleagues $^{19}$ demonstrated a similar effect among African-Americans. A study on birth outcomes among African-American mothers in Chicago in 1991 suggested that residence in areas with low African-American racial density was associated with increased risk for adverse birth outcomes.

Borrowing from the literature about the association between community context and the health and birth outcomes of Mexican-Americans, we used data from the state of Michigan, the state with the largest concentration of Arab-Americans in the USA, to assess the relation between maternal community context and risk for LBW among AEMs. We reasoned that if observations among Mexican-American populations are generalisable, we might expect that Arab-Americans living in areas of high Arab-American concentration would be less likely to be acculturated and hence to have a lower risk of adverse birth outcomes than Arab-Americans in areas less densely populated by members of their ethnic group. Therefore, we considered the relation between maternal residence in Dearborn, Michigan, the city with the largest Arab-American concentration in the USA ${ }^{20}$ and risk for LBW among AEM. We also considered the relation between maternal residence in the zip code with the largest proportion of AEM in Dearborn and risk for LBW among AEM. 
Table 2 Multivariable logistic regression models showing associations between covariates of interest and risk of low birth weight among Arab-ethnicity mothers in Michigan between 2000 and 2005

\begin{tabular}{|c|c|c|c|c|c|c|c|c|}
\hline & \multicolumn{4}{|c|}{ Dearborn } & \multirow[b]{2}{*}{$\mathbf{O R}$} & \multirow{2}{*}{$\begin{array}{l}48126 \\
95 \% \mathrm{Cl}\end{array}$} & \multirow[b]{2}{*}{ OR } & \multirow[b]{2}{*}{$95 \% \mathrm{Cl}$} \\
\hline & OR & $95 \% \mathrm{Cl}$ & OR & $95 \% \mathrm{CI}$ & & & & \\
\hline \multicolumn{9}{|l|}{ Dearborn } \\
\hline \multicolumn{9}{|l|}{ No (reference) } \\
\hline Yes & 0.84 & 0.74 to 0.95 & 0.85 & 0.75 to 0.97 & & & & \\
\hline \multicolumn{9}{|l|}{48126 zip code } \\
\hline \multicolumn{9}{|l|}{ No (reference) } \\
\hline Yes & & & & & 0.79 & 0.69 to 0.90 & 0.81 & 0.71 to 0.93 \\
\hline \multicolumn{9}{|l|}{ Parity } \\
\hline \multicolumn{9}{|l|}{0 (reference) } \\
\hline 1 & & & 0.80 & 0.70 to 0.92 & & & 0.80 & 0.70 to 0.92 \\
\hline 2 & & & 0.74 & 0.62 to 0.87 & & & 0.74 & 0.63 to 0.87 \\
\hline $3+$ & & & 0.70 & 0.58 to 0.84 & & & 0.70 & 0.58 to 0.84 \\
\hline Unknown & & & 1.11 & 0.57 to 2.15 & & & 1.11 & 0.57 to 2.16 \\
\hline \multicolumn{9}{|l|}{ Marital status } \\
\hline \multicolumn{9}{|l|}{ Unmarried (reference) } \\
\hline Married & & & 1.02 & 0.78 to 1.35 & & & 1.02 & 0.78 to 1.34 \\
\hline \multicolumn{9}{|l|}{ Maternal age $†$} \\
\hline$<20$ & & & 1.29 & 1.01 to 1.64 & & & 1.28 & 1.01 to 1.63 \\
\hline \multicolumn{9}{|l|}{ 20-25 (reference) } \\
\hline $26-30$ & & & 1.05 & 0.90 to 1.23 & & & 1.05 & 0.90 to 1.23 \\
\hline $31-35$ & & & 1.23 & 1.04 to 1.46 & & & 1.23 & 1.04 to 1.46 \\
\hline $36-40$ & & & 1.39 & 1.13 to 1.70 & & & 1.39 & 1.13 to 1.70 \\
\hline $41+$ & & & 1.88 & 1.40 to 2.53 & & & 1.88 & 1.40 to 2.52 \\
\hline \multicolumn{9}{|l|}{ Education } \\
\hline$<11$ years & & & 1.25 & 1.00 to 1.56 & & & 1.25 & 1.00 to 1.56 \\
\hline GED* or equivalent & & & 1.05 & 0.85 to 1.29 & & & 1.05 & 0.86 to 1.29 \\
\hline College & & & 1.09 & 0.89 to 1.32 & & & 1.09 & 0.89 to 1.33 \\
\hline \multicolumn{9}{|c|}{ Masters or above (reference) } \\
\hline Unknown & & & 0.83 & 0.56 to 1.22 & & & 0.82 & 0.56 to 1.22 \\
\hline \multicolumn{9}{|l|}{ Place of birth } \\
\hline Foreign & & & 0.87 & 0.76 to 1.00 & & & 0.88 & 0.77 to 1.01 \\
\hline \multicolumn{9}{|l|}{ USA (reference) } \\
\hline \multicolumn{9}{|l|}{ Tobacco use } \\
\hline \multicolumn{9}{|l|}{ None (reference) } \\
\hline Yes & & & 0.88 & 0.67 to 1.14 & & & 0.88 & 0.68 to 1.14 \\
\hline
\end{tabular}

As a control, to ensure that any observable associations were not due to some other feature of the focal communities themselves, we replicated all analyses among non-Arab white mothers (NAWM) in Michigan.

\section{METHODS}

\section{Data}

The Arab American Birth Outcomes Study collected data on all births in the State of Michigan between September 2000 and March 2005. Data were compiled from the birth records of the State of Michigan by the Michigan Department of Community Health (MDCH).

The primary health indicator of interest was LBW. Infants weighing $2500 \mathrm{~g}$ or less at birth were considered LBW. Birth registry data in the state of Michigan include information on race, ethnicity and Arab ancestry. Self-reported Arab ancestry was used to determine AE persons. Other covariates collected were the following: marital status (categorised as married or not married) at parturition, parity (categorised as $0,1,2$ or 3 or more previous children), maternal age (categorised as <20, 20-25, 26-30, $31-35,36-40$ and 41 or older), maternal education (categorised as <11 years, General Educational Development (GED) or equivalent, college, masters or above or unknown), maternal tobacco use during pregnancy (categorised as yes or no), maternal birthplace (categorised as USA or foreign) and maternal zip code.

We used zip code data to code our two community context covariates. First, the city of Dearborn contains the following zip codes: 48120, 48121, 48123, 48124, 48126 and 48128. Zip code data were used to code maternal residence inside or outside Dearborn. Second, we calculated the proportion of women who were $\mathrm{AE}$ who gave birth in each zip code within Dearborn, and used maternal residence within the zip code with the highest proportion of AEM as our second community context covariate.

This study was reviewed by the Health Science Institutional Review Board of the University of Michigan and the Institutional Review Board of the Michigan Department of Community Health.

\section{Analysis}

First, we calculated univariate statistics to describe our sample. Second, we used bivariate $\chi^{2}$ tests to identify significant associations $(\alpha=0.05)$ between each of the covariates of interest and LBW. Third, we used multivariable logistic regression models of LBW to assess the relation between each community context 
Table 3 Multivariable logistic regression models showing associations between covariates of interest and risk of low birth weight among non-Arab white mothers in Michigan between 2000 and 2005

\begin{tabular}{|c|c|c|c|c|c|c|c|c|}
\hline & \multicolumn{4}{|c|}{ Dearborn } & \multicolumn{4}{|c|}{48126} \\
\hline & $\overline{\mathbf{O R}}$ & $95 \% \mathrm{CI}$ & $\mathbf{O R}$ & $95 \% \mathrm{CI}$ & $\overline{\mathbf{O R}}$ & $95 \% \mathrm{Cl}$ & OR & $95 \% \mathrm{CI}$ \\
\hline \multicolumn{9}{|l|}{ Dearborn } \\
\hline \multicolumn{9}{|l|}{ No (reference) } \\
\hline Yes & 0.90 & 0.79 to 1.02 & 0.93 & 0.82 to 1.06 & & & & \\
\hline \multicolumn{9}{|l|}{48126 zip code } \\
\hline \multicolumn{9}{|l|}{ No (reference) } \\
\hline Yes & & & & & 0.89 & 0.69 to 1.15 & 0.88 & 0.68 to 1.14 \\
\hline \multicolumn{9}{|l|}{ Parity } \\
\hline \multicolumn{9}{|l|}{0 (reference) } \\
\hline 1 & & & 0.79 & 0.77 to 0.81 & & & 0.79 & 0.77 to 0.81 \\
\hline 2 & & & 0.82 & 0.80 to 0.85 & & & 0.82 & 0.80 to 0.85 \\
\hline $3+$ & & & 0.96 & 0.93 to 1.00 & & & 0.96 & 0.93 to 1.00 \\
\hline Unknown & & & 1.27 & 1.07 to 1.51 & & & 1.27 & 1.07 to 1.51 \\
\hline \multicolumn{9}{|l|}{ Marital status } \\
\hline \multicolumn{9}{|c|}{ Unmarried (reference) } \\
\hline Married & & & 0.82 & 0.80 to 0.85 & & & 0.82 & 0.80 to 0.85 \\
\hline \multicolumn{9}{|l|}{ Maternal age $†$} \\
\hline$<20$ & & & 1.03 & 0.98 to 1.07 & & & 1.03 & 0.98 to 1.07 \\
\hline \multicolumn{9}{|l|}{$20-25$ (reference) } \\
\hline $26-30$ & & & 1.11 & 1.07 to 1.14 & & & 1.11 & 1.07 to 1.14 \\
\hline $31-35$ & & & 1.24 & 1.20 to 1.29 & & & 1.24 & 1.20 to 1.29 \\
\hline $36-40$ & & & 1.50 & 1.44 to 1.56 & & & 1.50 & 1.44 to 1.56 \\
\hline $41+$ & & & 1.86 & 1.74 to 1.98 & & & 1.86 & 1.74 to 1.98 \\
\hline \multicolumn{9}{|l|}{ Education } \\
\hline$<11$ years & & & 1.21 & 1.15 to 1.27 & & & 1.21 & 1.15 to 1.27 \\
\hline GED* or equivalent & & & 1.06 & 1.02 to 1.10 & & & 1.06 & 1.02 to 1.10 \\
\hline College & & & 0.98 & 0.95 to 1.02 & & & 0.98 & 0.95 to 1.02 \\
\hline \multicolumn{9}{|c|}{ Masters or above (reference) } \\
\hline Unknown & & & 1.34 & 1.23 to 1.45 & & & 1.34 & 1.23 to 1.45 \\
\hline \multicolumn{9}{|l|}{ Place of birth } \\
\hline Foreign & & & 0.88 & 0.85 to 0.92 & & & 0.88 & 0.85 to 0.92 \\
\hline \multicolumn{9}{|l|}{ USA (reference) } \\
\hline \multicolumn{9}{|l|}{ Tobacco use } \\
\hline \multicolumn{9}{|l|}{ None (reference) } \\
\hline Yes & & & 1.60 & 1.56 to 1.64 & & & 1.6 & 1.56 to 1.64 \\
\hline
\end{tabular}

individually and adjusted for all other covariates. This yielded two separate multivariable logistic regression models of LBW. The first compared residence in Dearborn to residence in the rest of the state of Michigan. The second compared residence in the zip code with the highest proportion of AEM to residence in the rest of the state. As a control, we also conducted each of the above analyses using data about all births among NAWM in Michigan during our study period.

SAS 9.1 (SAS Institute, Cary, North Carolina) was used to carry out all statistical analyses. Statistical significance was set at the $\mathrm{p}=0.05$ level.

\section{RESULTS}

Complete data for analyses were available for 21617 births to AEMs. Among women living in Dearborn who gave birth in Michigan between 2000 and 2005, 59.7\% were AE. Of all zip codes in Dearborn, 48126 was the zip code with the highest proportion of AEM with $80.8 \%$ of the births between 2000 and 2005 in 48126 to AEM.

Table 1 shows the univariate statistics and bivariate $\chi^{2}$ analyses between each of our covariates and LBW among AEM and NAWM, individually. Univariate statistics showed the following: overall, the prevalence of LBW was 6.5\% among AEM and 6.8\% among NAWM; $30.6 \%$ of all AEM in Michigan lived in Dearborn, while $0.7 \%$ of all NAWM in Michigan lived in Dearborn; $24.7 \%$ of all AEM lived in 48126 as compared with $0.2 \%$ of all NAWM.

In $\chi^{2}$ models, residence in Dearborn $(p=0.004)$ and 48126 $(\mathrm{p}<0.001)$ was associated with LBW among AEM but not NAWM. All other variables were associated with LBW among NAWM, but only parity $(p<0.001)$, maternal age $(p<0.001)$ and maternal birthplace $(p=0.034)$ were associated with LBW among AEM.

Table 2 shows the multivariable regression models assessing the relation between covariates of interest (residence in Dearborn or residence in 48126) and LBW taking into account all other covariates among AEM. In separate multivariable models, residence in Dearborn (OR $=0.85,95 \%$ CI 0.75 to 0.97 ) and residence in 48126 (OR=0.81, 95\% CI 0.71 to 0.93 ) were both associated with lower LBW risk compared with residence in the rest of Michigan.

Table 3 shows the multivariable regression models of LBW by residence in Dearborn or residence in 48126 , and other covariates among NAWM. Neither residence in Dearborn nor 48126 was associated with LBW risk compared with residence in the rest of Michigan in multivariable models among NAWM. 


\section{DISCUSSION}

In a study of 21617 births in Michigan between 2000 and 2005, we found that among AEMs, maternal residence in the city of Dearborn, Michigan, the city with the highest proportion of Arab-Americans in the USA, was associated with a 15\% lower risk for LBW compared with maternal residence among Arab-Americans in the rest of Michigan. Moreover, among AEM, maternal residence in the zip code 48126, the zip code with the highest proportion of AEM in Michigan, was associated with a 19\% lower risk for LBW compared with residence outside this zip code. Neither residence in Dearborn, Michigan nor residence in 48126 was associated with a lower risk for LBW among NAWM.

Although we know of no published studies that explicitly assess the effects of community context on the birth outcomes of Arab-Americans, our study does corroborate the findings of Peak and Weeks ${ }^{15}$ who assessed the effects of community context on the birth outcomes of Mexican-Americans in San Diego County, California. They found that residence in Hispanic enclaves was associated with a lower risk for LBW compared with residence in other localities among Mexican-American women but not among non-Hispanic white women.

Our finding that AEM in Dearborn were at lower risk for LBW than their counterparts outside this Arab-American-dense locality may be best interpreted within the broader framework of the acculturation-risk association for adverse birth outcomes among ethnic minorities. ${ }^{5-10} 13$ Ethnic enclaves are characterised by the cultural distinction they maintain from surrounding areas. ${ }^{21}$ Thus, ethnic inhabitants of these localities are more likely to maintain cultural features that may protect against adverse birth outcomes than their ethnic counterparts in other localities. Following this line of reasoning, it is possible that AEM in Dearborn, Michigan are less acculturated than their counterparts in other localities and that this difference in acculturation accounts for the findings documented here.

It is important to consider the following limitations when interpreting our findings. First, we used a limited covariate set. Of particular note, the only traditional socio-economic status variable that we included was maternal education; the paucity of socio-economic variables in our study could have allowed for residual confounding of the association between community context and risk for LBW among AEM. Second, our work is limited by the accuracy of birth-certificate data recorded in vital registry files. Although it has been shown that demographic data, including maternal ethnicity, from birth certificates is highly accurate, it has been shown that tobacco-use estimates in birth-certificate data can be unreliable. ${ }^{22-24}$ Third, although we hypothesise that relative acculturation may mediate the relation between community context and risk for LBW among Arab-American mothers, this cannot be verified with the data presented. It is also plausible that other factors, such as relative deprivation, may mediate the relation between community context and risk for LBW among this ethnic group.

Despite these limitations, our findings have several implications for future research. First, investigators interested in the relation between community context and the birth outcomes of Arab-Americans could assess the relation between community context and more specific birth metrics, such as PTB or intrauterine growth retardation. Second, investigators interested in the determinants of adverse birth outcomes among Arab-Americans might explore factors that may mediate the relation between community context and risk for LBW among AEM, such as metrics of acculturation or of relative deprivation. Third, investigators might consider neighbourhood-level studies that assess the relation between the concentration of

\section{What is already known on this subject}

Arab ethnicity is associated with a lower risk for adverse birth outcomes compared with non-Arab Caucasians in the USA and Europe. Little is known about the determinants of adverse birth outcomes among Arab-American mothers. It has been shown that community context is associated with risk for low birth weight among other ethnic groups in the USA. In this study, we used data on all births between 2000 and 2005 in Michigan, the state with the highest concentration of Arab-Americans in the USA, to assess the relation between community context and risk of low birth weight among Arab-American mothers.

\section{What this study adds}

We found that among Arab-American mothers, residence in Dearborn, the city with the highest Arab-American concentration in Michigan, was associated with a lower risk for low birth weight compared with residence in the rest of the state. We also found that residence in the zip code "48126," the zip code with the highest concentration of Arab-Americans in Dearborn, was associated with a lower risk of low birth weight among Arab-American mothers compared with residence in the rest of the state. There was no association between residence in either of these two localities and risk for low birth weight among nonArab Caucasians. We hypothesise that differences in relative acculturation between Arab-American mothers in Dearborn and those in the rest of the state may mediate the association between community context and risk for low birth weight. Future research might explicitly assess the potential for several factors, such as acculturation or relative deprivation, to mediate this relation.

Arab-Americans in neighbourhoods and risk for adverse birth outcomes among Arab-Americans in those contexts. Fourth, investigators interested in the health of Arab-Americans could consider the effects of community context on other health metrics among this ethnic group.

Acknowledgements The authors thank $G$ Copeland and $G$ Radford from the Michigan Department of Community Health for their help acquiring the data.

Funding $\mathrm{NIH}$.

Competing interests None.

Ethics approval Ethics approval was provided by the Health Science Institutional Review Board of the University of Michigan and the Institutional Review Board of the Michigan Department of Community Health.

Provenance and peer review Not commissioned; externally peer reviewed.

\section{REFERENCES}

1. El Reda DK, Grigorescu V, Posner SF, et al. Lower rates of preterm birth in women of Arab ancestry: an epidemiologic paradox-Michigan, 1993-2002. Matern Child Health J 2007:11:622-7.

2. Guendelman S, Buekens P, Blondel B, et al. Birth outcomes of immigrant women in the United States, France, and Belgium. Matern Child Health $J$ 1999;3:177-87

3. El-Sayed AM, Hadley C, Galea S. Birth outcomes among Arab-American before and after the terrorist attacks of September 11, 2001. Ethn Dis 2008;18:348-56.

4. El-Sayed AM, Galea S. Explaining the low risk of preterm birth among Arab Americans in the US: an analysis of 617,451 births. Pediatrics 2009;123:e438-45. 
5. Zambrana RE, Scrimshaw SC, Collins N, et al. Prenatal health behaviors and psychosocial risk factors in pregnant women of Mexican origin: the role of acculturation. Am J Public Health 1997:87:1022-6.

6. Cobas JA, Balcazar H, Benin MB, et al. Acculturation and low-birthweight infants among Latino women: a reanalysis of HHANES data with structural equation models. Am J Public Health 1996;86:394-6.

7. Balcazar $\mathbf{H}$, Krull JL, Peterson G. Acculturation and family functioning are related to health risks among pregnant Mexican American women. Behav Med 2001;27:62.

8. Balcazar H, Krull JL. Determinants of birth-weight outcomes among Mexican-American women: examining conflicting results about acculturation. Ethn Dis 1999:9:410-22.

9. Guendelman S, Malin C, Herr-Harthorn B, et al. Orientations to motherhood and male partner support among women in Mexico and Mexican-origin women in the United States. Soc Sci Med 2001:52:1805-13.

10. de la Rosa IA. Perinatal outcomes among Mexican Americans: a review of an epidemiological paradox. Ethn Dis 2002;12:480-7.

11. Baruffi G, Kieffer EC, Alexander GR, et al. Changing pregnancy outcomes of Samoan women in Hawaii. Paediatr Perinat Epidemiol 1999:13:254-68.

12. Kottak CP. Windows on humanity. New York: McGraw Hill, 2005.

13. Scribner R, Dwyer JH. Acculturation and low birthweight among Latinos in the Hispanic HANES. Am J Public Health 1989:79:1263-7.

14. Hyman I, Dussault G. The effect of acculturation on low birth weight in immigrant women. Can J Public Health 1996;87:158-62.
15. Peak C, Weeks JR. Does community context influence reproductive outcomes of Mexican origin women in San Diego, California? J Immigr Health 2002;4:125-36.

16. Eschbach K, Ostir GV, Patel KV, et al. Neighborhood context and mortality among older Mexican Americans: is there a barrio advantage? Am J Public Health 2004;94:1807-12

17. Cagney KA, Browning CR, Wallace DM. The Latino paradox in neighborhood context: the case of asthma and other respiratory conditions. Am J Public Health 2007:97:919-26.

18. Ostir GV, Eschbach K, Markides KS, et al. Neighbourhood composition and depressive symptoms among older Mexican Americans. J Epidemiol Community Health 2003;57:987-92.

19. Pickett KE, Collins JW Jr, Masi CM, et al. The effects of racial density and income incongruity on pregnancy outcomes. Soc Sci Med 2005;60:2229-38.

20. de la Cruz G, Patricia, Brittingham A. The Arab population: 2000. Washington DC:US Census Bureau, 2003

21. Logan JR, Alba RD, Zhang W. Immigrant Enclaves and ethnic enclaves in New York and Los Angeles. Am Sociol Rev 2002;67:299-322.

22. Buescher PA, Taylor KP, Davis MH, et al. The quality of the new birth certificate data: a validation study in North Carolina. Am J Public Health 1993;83:1163-5.

23. Northam S, Knapp TR. The reliability and validity of birth certificates. J Obstet Gynecol Neonatal Nurs 2006:35:3-12.

24. Reichman NE, Hade EM. Validation of birth certificate data. A study of women in New Jersey's HealthStart program. Ann Epidemiol 2001;11:186-93. 